\title{
Olgu bildirimi \\ Incontinentia pigmenti: olgu bildirimi ve 5 yıllık takip
}

\author{
Ayşegül Sarı, ${ }^{1}$ Salih Çelik ${ }^{2}$ \\ ${ }^{1}$ Periodontoloji Anabilim Dalı, Diş Hekimliği Fakültesi, Mustafa \\ Kemal Üniversitesi, Hatay, ${ }^{2}$ Ağız ve Çene Cerrahisi Anabilim \\ Dalı, Diş Hekimliği Fakültesi, Akdeniz Üniversitesi, Antalya, \\ Türkiye
}

\section{ÖZET}

TANITIM: Incontinentia pigmenti (Bloch-Sulzberger Sendromu) X-kromozomuna bağlı dominant geçiş gösteren, ektodermal ve mezodermal kökenli organ tutulumlu bir hastalıktır. Cilt, göz, diş ve merkezi sinir sistemini etkiler.

Olgu BildiRimi: Hasta, Incontinentia Pigmenti tanısıyla Mustafa Kemal Üniversitesi Tıp Fakültesi Dermatoloji kliniğinden Mustafa Kemal Üniversitesi Diş Hekimliği Fakültesi Periodontoloji kliniğine, ağız içerisinde diş germlerinde ve kretler bölgesinde anomali olup olmadığının değerlendirilmesi için gönderildi. Hasta 5 yıl boyunca farklı yaşlarda kliniğimizde takip edilerek; 42 günlükken, 6 aylıkken ve 5 yaşındayken tarafımızdan görüldü. Hastanın farklı kontrol seanslarında yapılan ağız dışı muayenesinde, ikinci evre eritemli, hiperkeratotik papül ve plaklar hastanın kol ve bacaklarında mevcutken; farklı evrelerde seyreden, lineer yerleşimli hiperpigmente ve hipopigmente maküler lezyonlar izlendi. Hastanın ağız içi muayenesinde dişsiz döneminde kretlerde ve damakta herhangi bir anomali gözlenmedi, dişlenme döneminde ise kama şeklinde dişlerin mevcudiyeti, ve ayrıca oligodonti görüldü. Beş yıllık takip sürecinde hastanın vücut ve mental gelișiminde yaşıtlarına kıyasla herhangi bir yetersizlik tespit edilmedi.

Sonuç: Incontinentia Pigmenti'de görülen dental anomalilerle hastalığın erken teşhisi yapılabilir. Hastalığın özel bir tedavisi olmayıp, birçok vücut sistemini etkilemesi nedeniyle interdisipliner yaklaşımlarla takip ve tedavi gerektirmektedir.

AnAHTAR Kelimeler: Bloch-Sulzberger sendromu; diş anomalileri; Incontinentia pigmenti

Kaynak Göstermek İçin: Sarı A, Çelik S. Incontinentia pigmenti: olgu bildirimi ve 5 yıllık takip. Acta Odontol Turc 2017;34(3):109-12

Makale gönderiliș tarihi: 26 Ağustos 2016; Yayına kabul tarihi: 18 Şubat 2017 *iletişim: Ayşegül Sarı, Mustafa Kemal Üniversitesi, Diş Hekimliği Fakültesi,

Periodontoloji Anabilim Dalı, 31040, Hatay, Türkiye;

E-posta: aysglsr@gmail.com
EdiтöR: Neşe Akal, Gazi Üniversitesi, Ankara, Türkiye

YAYIN HAKKI: @ 2017 Sarı ve Çelik. Bu eserin yayın hakkı Creative Commons Attribution License ile ruhsatlandırılmıştır. Sınırsız kullanım, dağıtım ve her türlü ortamda çoğaltım, yazarlar ve kaynağın belirtilmesi kaydıyla serbesttir.

[Abstract in English is at the end of the manuscript]

\section{Giriş}

Incontinentia Pigmenti (IP) veya Bloch-Sulzberger sendromu nadir görülen $X$ kromozomuna bağlı dominant geçiş gösteren, genellikle bayanlarda görülen bir genodermotozdur. IP'ye NEMO geninde bulunan Xq28 odağındaki mutasyonlar neden olur., ${ }^{1,2}$ Mutasyon gen genellikle erkekler için uterusta öldürücüdür, bu yüzden genellikle karşılaşılan vakalar kız çocuklarıdır (\%97). ${ }^{1,2}$ Sistemik bir hastalık olan IP, ektodermik ve mezodermik orijinli cilt, diş, göz ve santral sinir sistemi dokularını etkiler. ${ }^{3,4}$

Incontinentia Pigmenti'de cilt lezyonları dört klasik aşamada toplanır. Bazı vakalarda bu aşamaların hepsi takip edilmez. Birinci aşamada eritem, veziküller ve tipik doğrusal model görünen kabarcıklar, ikinci aşamada papüller, verrüköz lezyonlar ve hiperkeratozlar, üçüncü aşamada hiperpigmentasyon, dördüncü aşamada hipopigmentasyon ve deri atrofisi şeklinde lezyonlar izlenir. Bu aşamaların hepsinde, deri lezyonları Blaschko Çizgileri'ni takip eğilimindedir. ${ }^{5}$

Incontinentia Pigmenti hastalarında, dermatolojik değişiklikleri takiben dental anomalilerin görülme sıklığı $\% 80$ oranındadır. ${ }^{4}$ Hem daimi hem süt dişlenme dönemlerinde kısmi anodontiler, konik dişler ve diş sürmesinde gecikmeler görülebilmektedir. ${ }^{5,6}$ Bazı vakalarda çoklu diş çürükleri ve ufalanan dişler rapor edilmiştir. ${ }^{7}$ Bunların dışında arka dişlerde fazla tüberkül, konum anomalileri, dikey oklüzyon kaybı, diş minesi anomalileri, sert ve yumuşak damak hipoplazileri, dudak-damak yarıkları, yutma ve ses bozuklukları görülebilen diğer anomalilerdir. ${ }^{8-11}$

Bu raporun amacı, IP teşhisli hastanın dermatolojik ve dental bulgularını ile bu bulguların seyrini sunmakla birlikte; bu tip hastalarda koruyucu dental tedavilerin önemini vurgulamaktır. 


\section{OLGU BiLdiRimi}

Kırk-iki günlük kız bebek hasta, IP tanısıyla, Mustafa Kemal Üniversitesi Tıp Fakültesi Dermatoloji Anabilim Dalından, Mustafa Kemal Üniversitesi Diş Hekimliği Fakültesi Periodontoloji Kliniğine ağız içerisinde, diş germlerinde ve kretler bölgesinde anomali olup olmadığını konsülte etmek için gönderilmişti. Hastanın ağız dışı muayenesinde kol ve bacaklarda lineer yerleşimli, eritemli zeminde hiperkerotatik papül ve plaklar, çenede eritemli papüllerin mevcudiyeti görüldü (Resim 1). Hastanın ağız içi muayenesinde dişsiz kret bölgelerinde ve damakta herhangi bir anomali gözlenmedi, ağız mukozası sağlıklıydı. Hastanın 6 ay sonraki kontrol seansında, ağız dışı muayenede gövdede blaschko çizgilerini takip eden hiperpigmente maküler lezyonlar; ekstremitelerde etrafı hiperpigmente halka ile çevrili ortası hipopigmente maküler lezyonlar görüldü. Çocuk nörologlarının yaptıkları değerlendirmelerde vücut gelişiminde ve mental durumunda herhangi bir yetersizlik saptamadıkları öğrenildi.

Ağız içi muayenesinde 2 üst ve 2 alt çenede olmak üzere kama şeklinde 4 adet dişin mevcut olduğu görüldü (Resim 2). Diş germlerini değerlendirmek amacıyla yapılacak radyolojik muayene için hasta çok küçük olduğundan film alınamadı. Hastanın annesine olabi- lecek dişsel anomalilerden (anodonti, konik dişler ve diş sürmesinde gecikmeler) bahsedildi. Çocuğun ağız hijyenin dişler ve periodontal dokular için oldukça önem arz ettiği, ağız hijyen uygulamalarında yapılan inmalin olası (anodonti risk tablosuna ilave olarak), az sayıdaki mevcut dişlerin de idamesini zorlaştıracağı ve kaybına sebep olabileceği vurgulandı. Hastanın ebeveyninden hastayı 6 aylık aralıklarla kontrol seanslarına getirmesi istenmesine rağmen hasta takipten çıktı. 6 aylıkken yapılan kontrolden uzun bir süre sonra, 5 yaşında ebeveynleri tarafından tekrar kliniğimize getirildi. Vücudunda önceki seanslardakilere nazaran daha büyük boyutlarda (en büyüğü 4×2 cm) kahverengimsi hiperpigmente maküler lezyonlar görüldü. Çenesinde hafif eritemli ve hiperkerotatik plak mevcuttu. Ön bölgedeki persiste süt dişlerinin çoğu konik görünümdeydi. Üst çenede süt lateral dişler, alt çenede sağ süt molar dişler, sol süt santral ve lateral- dişler mevcut değildi. Radyolojik muayenede 12, 16, 17, 22, 27, 31, 32, 36, 37, 41, 44, 45, 46 ve 47 no'lu diş germlerinin eksik olduğu görüldü (Resim 3). Hastanın ebeveynleri ağız hijyenine dikkat ettiği için periodontal dokularda herhangi bir enflamasyon ve diş çürüğüne rastlanmadı. Diş mineleri sağlıklı görünümdeydi. Hasta yer tutucu uygulaması için Pedodonti Anabilim Dalına yönlendirildi.

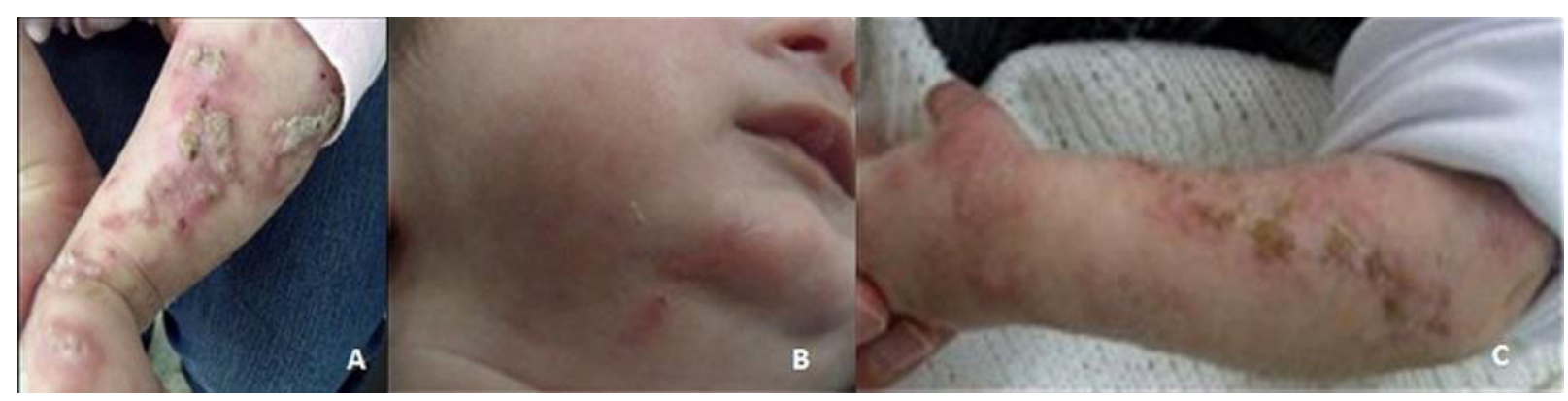

Resim 1. Hastanın 42 günlükken görüldüğü seans fotoğrafları; (A) bacak bölgesindeki cilt lezyonları, (B) yüz bölgesindeki cilt lezyonları, (C) kol bölgesindeki cilt lezyonları

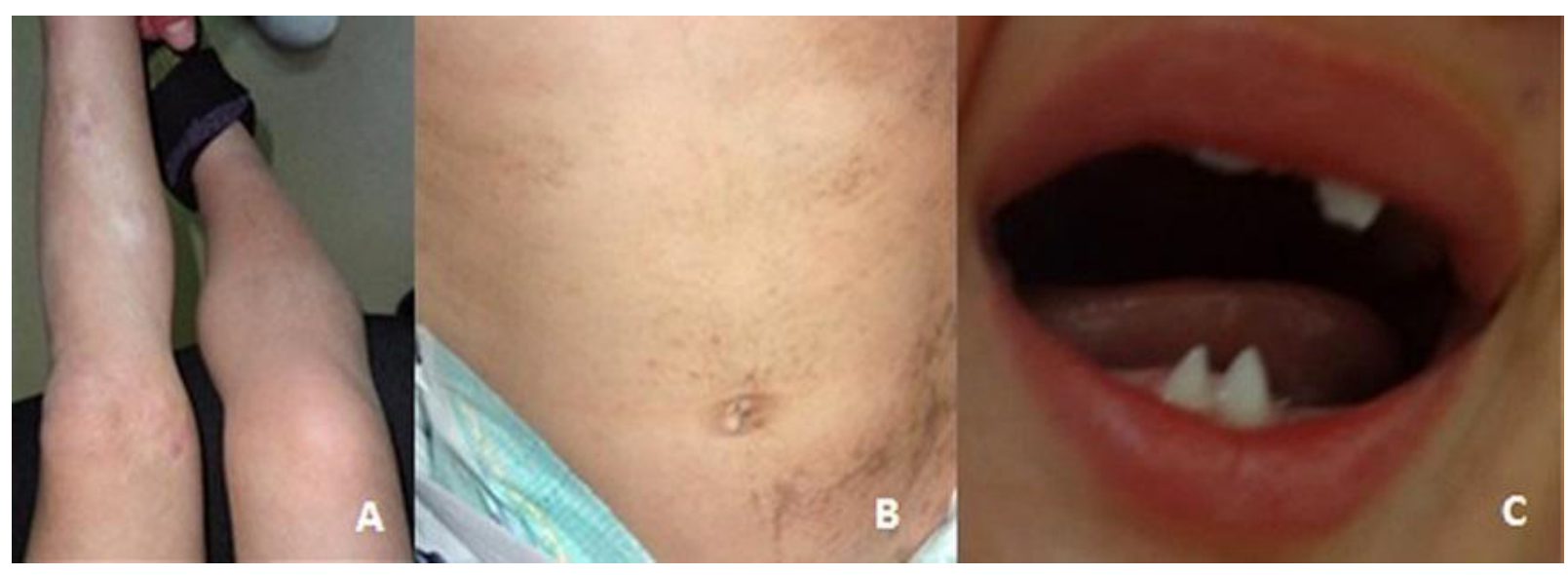

Resim 2. Hastanın 6 aylıkken görüldüğü seans fotoğrafları; (A) bacak bölgesindeki cilt lezyonları, (B) gövdede mevcut olan cilt lezyonları, (C) ağız-içi görüntüsü (konik dişler) 


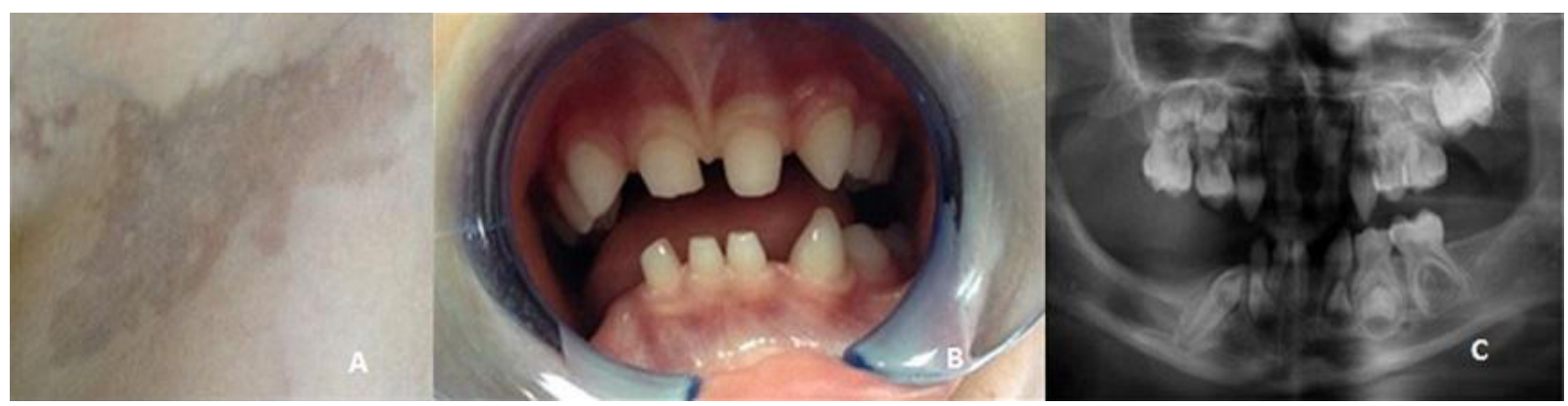

Resim 3. Hastanın 5 yaşındayken görüldüğü seans fotoğrafları; (A) hiperpigmente cilt lezyonları, (B) ağız-içi görüntüsü, (C) panoromik radyograf (konik dişler ve diş eksiklikleri)

\section{TARTIŞMA}

Incontinentia Pigmenti erken bebeklik döneminde ortaya çıkan ve deri, diş, saç, göz ve MSS gibi ektoderm kökenli organ ve dokuları etkileyen, nadir görülen X'e bağıı dominant geçişli multisistemik genetik bir hastalıktır. ${ }^{12,13}$ Hastalık ismini mikroskobik incelemelerde deride görülen morfolojik değişikliklerden almaktadır. ${ }^{13}$ Yaygınlığı 1/40,000 civarındadır. ${ }^{13,14}$ Erkeklerde genellikle fetal seyir gösterir, olguların \%95'ten fazlasını kız çocukları oluşturur. ${ }^{11}$ Bizim olgumuz da 42 günlük bir kız bebekti.

Blaschko çizgileri genellikle 4 dönemde incelenen tipik cilt lezyonları ile karakterizedir. Deri bulguları hastaların çoğunda doğumda mevcuttur ya da yaşamın ilk 2 haftası içerisinde meydana gelir. Bu 4 evre: veziküler dönem (doğumdan itibaren ya da kısa bir süre sonra); verrüköz dönem (2 ila 8 hafta); hiperpigmente dönem (birkaç aylıktan yetişkinliğe kadar) ve hipopigmente dönem (bebeklikten yetişkinliğe kadar) şeklindendir. ${ }^{15}$ Birinci ve ikinci evre lezyonları ortalama 4. ve 7. aylarda geriler. Bir hastada tüm evreler görülmeyebileceği gibi evreler iç içe geçmiş de olabilir. Birinci ve 3 . dönemler 2. ve 4. dönemlerden daha yaygın olarak görülür.1,16 Bizim olgumuzda literatürle uyumlu olarak doğum sırasında ekstremitelerde vezikülobülloz lezyonların varlığı bildirilmişti. Hasta 42 günlük iken Periodontoloji kliniğimize getirildiğinde bu lezyonların yerine hiperkeratotik plaklar görüldü. Bizim olgumuzun 6 . ay kontrolünde hipekeratotik lezyonların gerilediği yerine gövdede Blaschko çizgilerini takip eden ve hastalığa ismini veren kahverengi ve gri hiperpigmente maküler lezyonların belirdiği görüldü. Aynı zamanda alt ekstremitede etrafı hiperpigmente ortası hipopigmente maküler lezyonların varlığı tespit edildi. Hastanın 5 yaşındayken yapılan takip seansında daha büyük boyutlarda hiperpigmente maküler alanlar görüldü.

Mental retardasyon, şaşılık, mat-kırılgan saçlar ve anormal dişlenme hastalı̆̆ın diğer belirtilerindendir. ${ }^{17}$ Bizim olgumuzda Dermatoloji ve Göz Hastalıkları Anabilim Dallarının tetkik sonuçlarına göre saç ve göz tutulumu mevcut değildi, hastanın 6 aylıkken yapılan muayenesinde hafif konjunktivit saptandığı ve tedavisinin yapıldığı bildirildi. Hastanın Pediatri Anabilim Dalında yapılan muayenesinde mental fonksiyonlarının normal, nörogelişimsel basamakların yaşıtlarıyla uyumlu olduğu bildirilmişti.

Literatürde IP'de dental anomalilerin görülme oranının \%90'nın üzerinde olduğu bildirilmiştir. Russel ve Finn bu anomalilerin: dişlerin eksikliği, konik ve ilave tüberküllü posterior diş̧erin varlığı, dişlerin sürmesinin gecikmesi olarak üç ana başılık altında sınıflamışlardir. ${ }^{9}$

Bir çalışmada sistemik sağıklı çocuklarda \%6 oranında hipodonti görülürken, IP'li çocuklarda bu oranın \%43.1 olduğu; sistemik olarak sağlıklı çocuklarda konik dişlerin görülme oranı \%0.33 iken IP'li çocuklarda \%30.4 olduğu rapor edilmiştir. ${ }^{18} \mathrm{Her}$ iki dentisyonda hastalıktan etkilenirken, daimi dentisyon üzerinde daha şiddetli etkinlik gösterdiği bildirilmiş̧ir. Damak anomalileri, hipokalsifikasyonlar, yaygın çürükler bu hastalarda görülebilen diğer dişsel anomalilerdendir. ${ }^{7}$ Bizim olgumuzda hasta henüz 5 yaşında olduğu için sadece süt dişleri değerlendirildi ve literatürle uyumlu olarak hipodonti ve konik şekilli süt dişlerinin mevcut olduğu görüldü. Yumuşak ve sert damakta herhangi bir anomali görülmezken, hipokalsifikasyona da rastlanmadı.

Incontinentia Pigmenti dişlerin morfolojilerinde değişikliğe sebep olan sifiliz, ektodermal displazi gibi diğer konjenital hastalıklarla karıştııımamalıdır. Genetik testler, cilt lezyonları ve diğer sistemik komplikasyonların varlığıyla IP'nin ayırıcı tanısı yapılabilir. ${ }^{19}$

Incontinentia Pigmenti hastalarının tanı ve tedavisinde interdisipliner yaklaşım önemlidir. ${ }^{20} \mathrm{Bu}$ hastalığın erken teşhisinde dental anomaliler ön plana çıkabilir. Hastalığın takibi hipodonti ve hipokalsifikasyon gibi deformiteler nedeniyle mevcut dişlerin idamesi için önem arz etmektedir. Bu tür sendromlu hastalar diş hekimi tarafında dikkatle muayene edilmeli, mevcut ve sonrasında oluşabilecek olası durumlar için tedavi planı oluşturulmalıdır.

\section{SONUÇ}

Günümüzde IP'nin belirli bir tedavisi bulunmamaktadır. 
Hastalarda görülen deri lezyonları, göz, santral sinir sitemi ve dişlerde görülen anomaliler için hastaya interdisipliner bir yaklaşım gerekmektedir. Dişsel anomali oluşumlarının önüne geçilememekle birlikte, hastaya ve ebeveynlerine verilen ağız hijyeni eğitimiyle ve düzenli diş hekimi takibiyle dişlerin ve periodontal dokuların durumu optimum şekilde muhafaza edilebilir.

Çıkar çatışması: Yazarlar bu çalışmayla ilgili herhangi bir çıkar çatışmalarının bulunmadığını bildirmişlerdir.

\section{KAYNAKLAR}

1. Kitakawa D, Fontes PC, Magalhaes FA, Almeida JD, Cabral LA. Incontinentia pigmenti presenting as hypodontia in a 3-year-old girl: a case report. J Med Case Rep 2009;3:116.

2. Poziomczyk CS, Recuero JK, Bringhenti L, Maria FD, Campos CW, Travi GM, et al. Incontinentia pigmenti. An Bras Dermatol 2014;89:2636.

3. Curth $\mathrm{HO}$, Warburton $\mathrm{D}$. The genetics of incontinentia pigmenti. Arch Dermatol 1965;92:229-35.

4. Carney RG. Incontinentia pigmenti. A world statistical analysis. Arch Dermatol 1976;112:535-42.

5. Hadj-Rabia S, Froidevaux D, Bodak N, Hamel-Teillac D, Smahi A, Touil $\mathrm{Y}$, et al. Clinical study of 40 cases of incontinentia pigmenti. Arch Dermatol 2003;139:1163-70.

6. Gorlin RJ, Anderson JA. The characteristic dentition of incontinentia pigmenti. J Pediatr 1960;57:78-85.

7. Himelhoch DA, Scott BJ, Olsen RA. Dental defects in incontinentia pigmenti: case report. Pediatr Dent 1987;9:236-9.

8. Yamashiro T, Nakagawa K, Takada K. Case report: orthodontic treatment of dental problems in incontinentia pigmenti. Angle Orthod 1998;68:281-4.

9. Russell DL, Finn SB. Incontinentia pigmenti (Bloch-Sulzberger syndrome): a case report with emphasis on dental manifestations. J Dent Child 1967;34:494-500.

10. Chang JT, Chiu PC, Chen YY, Wang HP, Hsieh KS. Multiple clinical manifestations and diagnostic challenges of incontinentia pigmenti--12 years' experience in 1 medical center. J Chin Med Assoc 2008;71:45560.

11. Fusco F, Pescatore A, Bal E, Ghoul A, Paciolla M, Lioi MB, et al. Alterations of the IKBKG locus and diseases: an update and a report of 13 novel mutations. Hum Mutat 2008;29:595-604.

12. Landy SJ, Donnai D. Incontinentia pigmenti (Bloch-Sulzberger syndrome). J Med Genet 1993;30:53-9.

13. Buinauskiene J, Buinauskaite E, Valiukeviciene S. Incontinentia pigmenti (Bloch-Sulzberger syndrome) in neonates. Medicina (Kaunas) 2005;41:496-9.

14. Kim BJ, Shin HS, Won CH, Lee JH, Kim KH, Kim MN, et al. Incontinentia pigmenti: clinical observation of 40 Korean cases. J Korean Med Sci 2006;21:474-7.

15. Fusco F, Fimiani G, Tadini G, Michele D, Ursini MV. Clinical diagnosis of incontinentia pigmenti in a cohort of male patients. J Am Acad Dermatol 2007;56:264-7.
16. Baykal C. Genodermatozlar. Dermatoloji Atlası, 3. Baskı. İstanbul: Nobel Tıp Kitabevleri; 2004; p. 404-5.

17. Afshar H, Daneshpazhooh M, Kiani A, Aref $P$, Baniameri Z. Abnormal dentition in a boy with incontinentia pigmenti: case report. J Dent 2012;9:267-70.

18. Clayton JM. Congenital dental anomalies in 3557 children. J Dent Child 1956;23:206-8.

19. Macey-Dare LV, Goodman JR. Incontinentia pigmenti: seven cases with dental manifestations. Int J Paediatr Dent 1999;9:293-7.

20. Kara OK, Mutlu A, Gunel MK. The results of early physiotherapy on a child with incontinentia pigmenti with encephalocele. BMJ Case Reports 2010; doi: 10.1136/bcr.03.2010.2814.

\section{Incontinentia pigmenti: case report and 5-year follow-up}

\begin{abstract}
INTRODUCTION: Incontinentia Pigmenti (Bloch-Sulzberger Syndrome) is a disease of organ involvement with ectodermic and mesodermic origin, showing dominant transition based on the X-chromosome. It affects the skin, eyes, teeth, and central nervous system.
\end{abstract}

CAse Report: The patient diagnosed with Incontinentia Pigmenti was referred from the Department of Dermatology, Faculty of Medicine, Mustafa Kemal University to the Department of Periodontology, Faculty of Dentistry, Mustafa Kemal University to consult whether there was anomaly in tooth germs and crests in the mouth. The patient was followed in our clinic for 5 years (examinations at 42 days, 6 months and 5 years). In the extraoral examinations, second-grade hyperkeratotic erythematous papules and plaques on the arms and legs, and linearly-arranged hyperpigmented and hypopigmented macular lesions at various grades were seen. In the intraoral examinations, no anomalies were observed in the crests and the palate during the toothless period. However, during the dentition period, wedge-shaped teeth and oligodontia were observed. In the 5-year follow-up period, no deficiency was observed in the patient's body and mental development compared with the peers.

Conclusion: Early diagnosis of Incontinentia Pigmenti can be made through observation of the dental anomalies. There is no specific treatment of this disease. As it affects multiple systems of the human body, it requires monitoring and treatment with interdisciplinary approaches.

KEYWORDS: Bloch-Sulzberger syndrome; Incontinentia pigmenti; tooth abnormalities 